\title{
Metastatic Squamous Cell Carcinoma Located in the Groin
}

\author{
F.Hali ${ }^{1}$, Z.Kaddioui ${ }^{2 *}$, K.Baline ${ }^{3}$, F.Marnissi ${ }^{4}$, N.Benchekroun ${ }^{5}$, S.Chiheb ${ }^{6}$
}

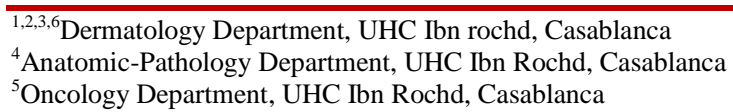

DOI: $10.36347 /$ simcr.2020.v08i08.007

| Received: 20.05.2020 | Accepted: 03.06.2020 | Published: 13.08.2020

*Corresponding author: Kaddioui Zina

Abstract

Squamous cell carcinoma is a rare entity, usually presents as an indurated and / or ulcerated plaque or as a vegetative proliferation associated with a chronic inflammatory process. It is localized preferentially on the sun-exposed areas. We report an original case of invasive squamous cell carcinoma located in the right inguinal region with fatal evolution.

Keywords: Metastatic squamous cell carcinoma, Chemotherapy, Groin.

Copyright @ 2020: This is an open-access article distributed under the terms of the Creative Commons Attribution license which permits unrestricted use, distribution, and reproduction in any medium for non-commercial use (NonCommercial, or CC-BY-NC) provided the original author and source are credited.

\section{CASE REPORT}

A 34-year-old patient with a history of unprotected sex, occasional smoking and alcoholism, who had a subcutaneous, inguinal, painless nodular lesion, 10 months ago, without inflammatory signs becoming ulcerated 7 months later. The dermatological examination revealed a budding ulcer $11 \mathrm{~cm}$ long, hollowed out with the fibrinous fundus, with indurated irregular edges and infiltrated at the inguinal fold with an extension towards the pubic region (Fig-1). Gynecological and proctological examinations were normal. The histological study concluded that squamous cell carcinoma (SCC) was moderately invasive (Fig-2a, b). A pelvic MRI showed a right inguinal tumor process extended to the large lip, infiltrating the skin and adjacent muscles with inguinal lymphadenopathy. As part of the extension evaluation, the thoracoabdominopelvic CT scan detected an irregular right inguinal mass with locoregional invasion and right necrotic inguinal lymphadenopathy, with no detectable secondary lesion. A PET scanner to remove a primitive had shown a magma of inguinal and femoral right hypermetabolic lymphadenopathies resulting in an ulcerated mass and a fistula on the skin. The patient underwent neo-adjuvant chemotherapy (5FU-Cisplatin) prior to surgery for excision and oncologic dissection of the lymph nodes with 3 injections of benzathine

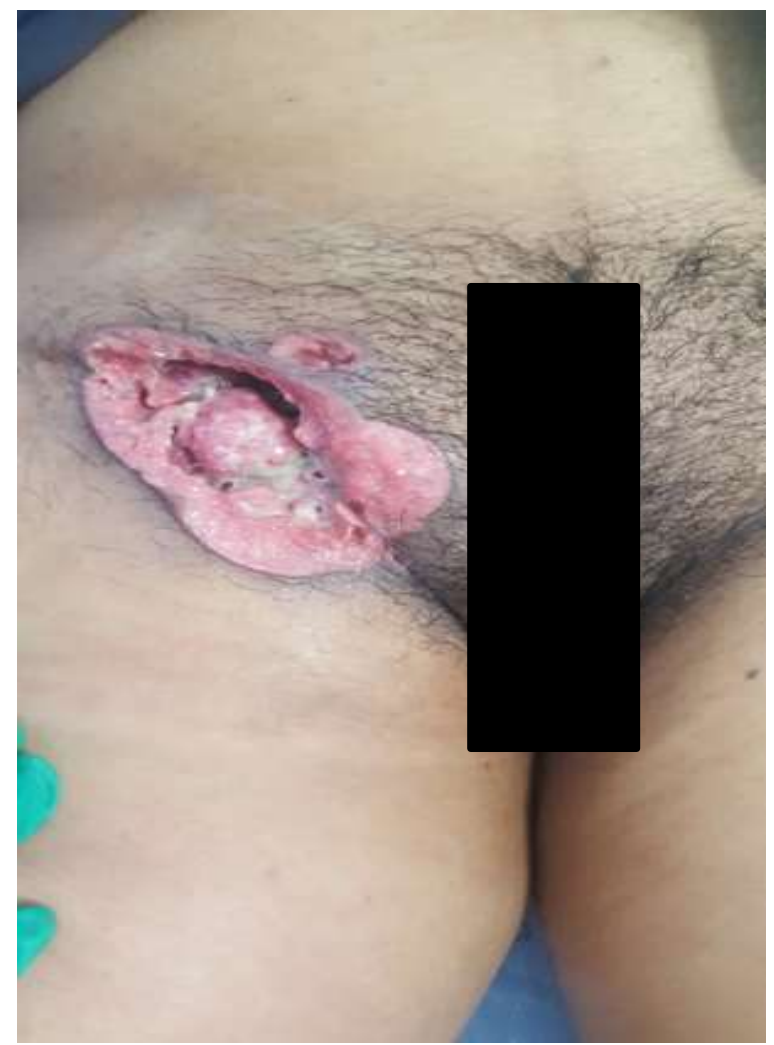

Fig-1 penicillin. The patient died during M6 chemotherapy. 

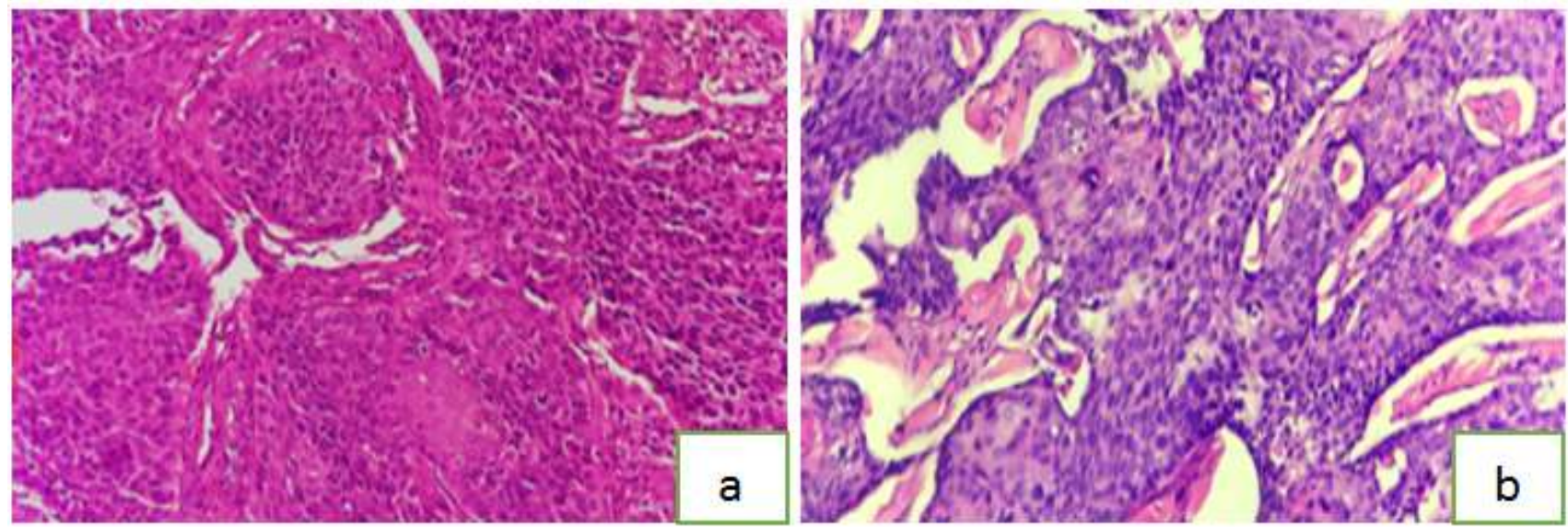

Fig-2a, b

\section{DISCUSSION}

Our case is particular in a way that the patient presented with a rare tumour with an atypical location, which made diagnosis and treatment difficult. We had a diagnostic difficulty with this patient because we could not decide on whether the patient presented with a metastatic lymphadenopathy of a SCC with cutaneous extension (primary tumour being unknown) or the tumour is primary cutaneous squamous carcinoma with an atypical location.

Carcinoma of unknown primary (CUP) is defined as metastatic deposits for which no site of origin could be detected even after performing all the possible tests. Cancer of unknown primary site (CUP) accounts for $4 \%-5 \%$ of all invasive cancers [1].

Peak age of incidence is 70 years and is equally common among males and females [2]. The present patient was middle aged lady. Autopsy series have shown that in cases of CUP, the lung is the most common site of primary followed by liver, pgancreas and gastrointestinal tract [3]. About 54\%- 60\% of CUPs are adenocarcinomas and $10 \%$ are SCC [4]. Approximately $10-40 \%$ of these patients have metastasis confined to the regional lymph nodes [5]. Of the inguinal lymph node region CUPs, about 10\%-15\% are of squamous cell origin [6]. Metastatic squamous cell carcinoma in the inguinal lymph node region could originate from malignancies of the anal canal; penis in males; cervix, vulva, and vagina in women; the skin of the perianal region; lower limbs; and lower half of the trunk.

In evaluation of metastatic spread to locoregional lymph nodes, CT/PET is significantly more accurate than CT. PET or PET/CT provides additional valuable information in confirming the diagnosis of CUP, especially in cases of squamous cell origin.

Skin squamous cell carcinoma located on the groin is very rare. Two cases of skin squamous cell carcinoma of the inguinal region have been described in the literature in immunocompromised patients [7]. Both cases were induced by HPV 16 . In our patient, for lack of means, we did not search for HPV on biopsies.

The treatment of epidermoid carcinoma of the inguinal region is non-consensual. The management of SCC locally advanced or metastatic is essentially based on combinaison chemoradiation therapy specialy for inoperable disease like the case of our patient. Chemotherapy, including cisplatin as a single agent or combined with 5-fluorouracil (5-FU), has shown some activity, but the results have not been confirmed in larger cohorts [8,9]. Our patient had squamous cell carcinoma inoperable right away and so we opted for a neoadjuvant chemotherapy based on $5 \mathrm{FU} /$ cisplatin.

The risk factor with the highest RR for disease specific death was diameter exceeding $20 \mathrm{~mm}$, pooor differentiation, location on the ear or lip, invasion beyond subcutaneous fat, and peri neural invasion [10]. Our patient had 2 factors for DSD that are diameter exceeding $20 \mathrm{~mm}$ and invasion beyond subcutaneous fat.

\section{Conclusion}

Even if metastatic squamous cell carcinoma in the inguinal lymph node region of CUP or cutaneous primitive remains a rare entity, but must be thought of any budding inguinal mass of rapid evolution and be able to indicate a cutaneous or lymph node biopsy and undertake the necessary investigations for rapid management to avoid any delay diagnosis as well as the fatal evolution.

\section{REFERENCES}

1. Greco FA, Hainsworth JD. Introduction: Unknown primary cancer. Semin Oncol. 2009;36(1):6-7.

2. Van de Wouw AJ, Janssen-Heijnen MLG, Coebergh JWW, Hillen HFP. Epidemiology of unknown primary tumours; incidence and population-based survival of 1285 patients in 
Southeast Netherlands, 1984-1992. Eur J Cancer. 2002;38(3):409- 13.

3. Freudenberg LS, Rosenbaum-Krumme SJ, Bockisch A, Eberhardt W, Frilling A. Cancer of Unknown Primary. In: Dresel S, éditeur. PET in Oncology [Internet]. Berlin, Heidelberg: Springer Berlin Heidelberg; 2008 [cité 29 janv 2020]. 193- 202. Disponible sur: http://link.springer.com/10.1007/978-3-54031203-1_15

4. Pentheroudakis G, Golfinopoulos V, Pavlidis N. Switching benchmarks in cancer of unknown primary: from autopsy to microarray. Eur J Cancer. sept 2007;43(14):2026- 36.

5. Abbruzzese JL, Abbruzzese MC, Hess KR, Raber MN, Lenzi R, Frost P. Unknown primary carcinoma: natural history and prognostic factors in 657 consecutive patients. J Clin Oncol. 1994;12(6):1272- 80.

6. Joseph K, Sawyer MB, Amanie J, Jones Thachuthara J, Ghosh S, Tai P. Carcinoma of unknown primary in the inguinal lymph node region of squamous cell origin: A case series. Pract Radiat Oncol. 2014;4(6):404- 8.
7. Croci-Torti A, Tamalet C, Segondy M, Dandurand M, Meunier L, Stoebner P-E. Human papillomavirus type 16-induced skin squamous cell carcinoma located on the groin of immunocompetent patients. $\mathrm{Br} \mathrm{J}$ Dermatol. 2014;170(3):753- 4.

8. Guthrie TH Jr, Porubsky ES, Luxenberg MN, Shah KJ, Wurtz KL, Watson PR. Cisplatin-based chemotherapy in advanced basal and squamous cell carcinomas of the skin: results in 28 patients including 13 patients receiving multi-modality therapy. J Clin Oncol, 1990;8(2):342-346.

9. Shin DM, Glisson BS, Khuri FR, Clifford JL, Clayman G, Benner SE, Forastiere AA, Ginsberg L, Liu D, Lee JJ, Myers J. Phase II and biologic study of interferon alfa, retinoic acid, and cisplatin in advanced squamous skin cancer. Journal of clinical oncology. 2002 Jan 15;20(2):364-70.

10. Thompson AK, Kelley BF, Prokop LJ, Murad MH, Baum CL. Risk Factors for Cutaneous Squamous Cell Carcinoma Recurrence, Metastasis, and Disease-Specific Death: A Systematic Review and Meta-analysis. JAMA Dermatol. 2016;152(4):419. 